\title{
Research on Venture Capital and Technological Innovation: Based on the ChiNext and Science and Technology
Innovation Board
}

\author{
Yanxi $\mathrm{He}^{1, *,{ }^{*}, \text { Xukun Wang }}{ }^{2, *}{ }^{*}$, Wenya Yang ${ }^{3, *}{ }^{*}$, , Qiyue Zhang ${ }^{4, *}{ }^{*}$
}

\author{
${ }^{1}$ The Faculty of Business and Economics, University of Sydney, Sydney, Sydney 2008, Australia \\ ${ }^{2}$ School of Economics, Chongqing Technology and Business University, Chongqing, 400067, China \\ ${ }^{3}$ Bell Honors School, Nanjing University of Posts and Telecommunications, Nanjing, 210023, China \\ ${ }^{4}$ Arts \& Science School, Syracuse University, Syracuse, 13244, United States \\ *Corresponding author'.Email: yahe4149@uni.sydney.edu.au@gmail.com \\ *Corresponding author2.Email: 2018016112@email.ctbu.edu.cn \\ *Corresponding author'.Email:Q18010407@njupt.edu.cn \\ *Corresponding authort.Email: qzhang51@syr.edu \\ These authors contributed equally.
}

\begin{abstract}
The impact of venture capital on the technological innovation of listed companies on the ChiNext and Science and Technology Innovation Board in 2019-2020 has been examined in this manuscript. This manuscript uses cross-sectional data of "Initial public offering" of listed companies on ChiNext and the Science and Technology Innovation Board and uses multiple regression analyses. In addition, important literature has been studied to obtain research results and empirical research methodologies such as descriptive statistical analysis and regression analysis. According to the study, the entry of venture capital has no significant impact on the number of patent applications filed by companies listed on the ChiNext Board. In contrast, the ratio of venture capital holdings positively affects the number of patent applications for companies listed on the Science and Technology Board. Hence, the venture capital industry should construct a highquality service system, expand its overall strength, actively invest in enterprises, and seek common growth with enterprises.
\end{abstract}

Keywords: Venture Capital, Enterprise, Technological Innovation, Patent Applications, Enterprise Growth

\section{INTRODUCTION}

Venture capital emerged relatively late in China. Since 1985, various venture capital companies have been formed from the central government to the local governments, the government to the private sector, large enterprises to small and medium-sized enterprises. After 1998, China's venture capital has also entered a phase of rapid development. The Small and Medium-sized Board (SME Board) was established in 2004, and in 2009 further promoted the growth and development of China's venture capital. In 2019, with the establishment of the Science and Technology Innovation Board and the reform of the registration system, the Chinese industry's venture capital had become more vigorous on the Growth
Enterprise Market and the Science and Technology Innovation Board. The study focused on the analysis of companies listed on listed companies on the ChiNext and SME boards. Science and Technology Innovation Board is a new sector that drives the innovation strategy in the country [1]. There has been no significant research on the creation boards. 2019 is almost ten years away from the opening of the ChiNext. Does venture capital have a different effect on the technological innovation of companies listed on ChiNext and the Science and Technology Innovation Board? Therefore, this article compares the Growth Enterprise Market and the Science and Technology Innovation Board to explore the impact of venture capital on the investment in the enterprise through the result of technological innovation [2]. 


\section{LITERATURE REVIEW}

There has been a lot of research on venture capital and enterprise technology innovation at the national and international levels. Different researches provided different research approaches and found different results [3]. There are three main points of view:

\subsection{Venture Capital Promotes Technological Innovation of Enterprises}

Liu selected the annual report data of 281 GEM companies from 2009 to 2014 to conduct an empirical analysis. The research found that venture capital has a certain role in promoting enterprise innovation. $\mathrm{Li}$ et al. built a multiple regression model based on the data of companies listed on the Growth Enterprise Market from 2011 to 2016. The analysis found that venture capital with a foreign investment background can increase the innovation investment of companies. Zhang used the data analysis of GEM and small and medium-sized enterprises to find that joint venture capital would linearly promote the technological innovation of enterprises. Zhang and Gu used global listed companies in China's information technology industry from 2005 to 2014 as a sample and used the full sample regression method to conclude that venture capital has a significant role in promoting corporate innovation [4].

\subsection{Venture Capital Has No Impact on the Technological Innovation of Enterprises}

Engel and Keilbach, by selecting companies that are relatively similar in terms of company life, asset size, and industries, etc., for comparative analysis, concluded that venture capital has no significant impact on innovation Research on the data of 378 listed companies found that the regression coefficient of venture capital's impact on corporate technological innovation was not significant. Cheng and Zou took listed companies on the ChiNext board in 2009-2014 as an example. They found that after venture capital entered the company, the impact on the company Neither investment nor output of innovation has a significant impact [5].

\subsection{Venture Capital Has a Restraining Effect on the Technological Innovation of Enterprises}

Wen and Feng believe that the entry of venture capital into the enterprise will grab the innovation ability of the enterprise, and its grabbing effects mainly include diluting the founder's equity and encroaching on company resources [6]. Therefore, the grabbing effect brought by the entry of venture capital is far greater than the value-added brought by it. The effect, that is, the entry of venture capital into the enterprise, will inhibit the enterprise's technological innovation.

\section{RESEARCH DESIGN}

\subsection{Samples and Data Sources}

The sample selected in this article is all listed companies on the ChiNext and Science and Technology Innovation Board issued and listed from January 2019 to November 2020. Due to the lack of individual data, we finally selected 139 effective samples of the ChiNext listed companies with venture capital participation [7]. There are 75 companies, 184 companies listed on the Science and Technology Innovation Board, and 128 companies with venture capital participation. The data of listed companies in this article comes from the Wind database, the prospectus of the listed company, and the company's annual report [8].

\subsection{Model Construction}

This research manuscript is mainly based on the model of the Growth Enterprise Market and the Science and Technology Innovation Board. It uses multiple linear regression models to examine the impact of venture capital on enterprise innovation inputs and outputs. The specific models are listed as follows.

$\mathrm{Yi}=\beta 0+\beta 1 V C+\sum$ Controls $+\varepsilon \mathrm{i}$

$\mathrm{Yi}=\beta 0+\beta 1$ VCshare $+\sum$ Controls $+\varepsilon \mathrm{i}$

$V C$ and $V C$ share represent venture capital and venture capital participation, and Controls represent a series of control variables. $\beta 0$ represent constant, $\beta 1$ represent coefficient and $\varepsilon i$ represent the error.

\subsection{Research Variables}

This paper measures the technological innovation of enterprises from innovation input and output, selects the proportion of $\mathrm{R} \& \mathrm{D}$ investment in operating income to measure the innovation input of enterprises and selects the logarithm of the number of patents to measure the innovation output of enterprises [9-10]. Two variables, venture capital and venture capital's shareholding ratio, are selected as explanatory variables to analyze the impact of venture capital on enterprise innovation. In addition, the four variables of asset scale, company life, weighted average return on net assets, and asset-liability ratio are selected as control variables.

\section{EMPIRICAL RESULTS AND ANALYSIS}

\subsection{Descriptive Statistical Analysis}

Table 1 is a descriptive analysis of the main variables. First of all, from the perspective of venture capital, the average values of variables such as venture capital participation and venture capital holding ratio of listed companies on the Sci-tech Innovation Board are higher than those of listed companies on the ChiNext [11]. From 
the perspective of the level of technological innovation of enterprises, the average value of variables such as the number of patents and the proportion of R\&D investment of listed companies on the Sci-tech Innovation Board is generally higher than that of the listed companies on the GEM [12].

\subsection{Regression Analysis}

This paper uses venture capital participation (VC), and venture capital shareholding ratio (VCshare) as explanatory variables to perform OLS regression on the logarithm of the number of patents (LNPAT) and the proportion of $R \& D$ investment (R\&D) of the two explained variables. From the regression results of listed companies on GEM in Table 2, it can be seen that the regression coefficients of venture capital participation in Model 1 and Model 2 are both positive but not significant. In contrast, the proportion of venture capital holdings affects $R \& D$ investment. The proportion has a significant negative effect. In models $3-8$, the format remains the same as models 1-2, but variables. Table 3 shows the regression results of venture capital participation (VC) and venture capital shareholding ratio (VCshare) of listed companies on the Science and Technology Innovation Board on the input and output of corporate technology innovation. It is also not significant, indicating that venture capital participation has no significant impact on the innovation input and output of listed companies on the Science and Technology Innovation Board. Judging from the regression results of the proportion of venture capital holdings on corporate technological innovation, the regression coefficient of the proportion of venture capital holdings to the number of patent applications is significantly positive, indicating that the proportion of venture capital holdings to the number of corporate patents is $10 \%$ There is a significant positive effect under the level. The proportion of venture capital holdings has no significant impact on the company's R\&D investment [13].

Table 1. Descriptive statistics of main variables

\begin{tabular}{lllllll}
\hline \multicolumn{1}{c}{ Variable } & & Obs & Mean & Std. Dev. & Min & Max \\
\hline \multirow{2}{*}{ Risk investment participation } & STI & 184 & 0.695 & 0.461 & 0.000 & 1.000 \\
& GEM & 139 & 0.539 & 0.502 & 0.000 & 1.000 \\
Venture capital shareholding ratio & STI & 184 & 0.066 & 0.093 & 0.000 & 0.652 \\
& GEM & 139 & 0.054 & 0.080 & 0.000 & 0.365 \\
Logarithm of patent number & STI & 184 & 1.849 & 0.497 & 0.477 & 3.910 \\
& GEM & 139 & 1.674 & 0.593 & 0.000 & 2.961 \\
Proportion of R\&D investment & STI & 184 & 0.075 & 0.019 & 0.559 & 0.106 \\
& GEM & 139 & 0.057 & 0.048 & 0.000 & 0.291 \\
\hline
\end{tabular}

\begin{tabular}{llllll}
\hline \multicolumn{5}{l}{ Table 2. The regression results of venture capital investment on the ChiNext to enterprise technological innovation } \\
\hline & Model & 1 & 2 & 3 & 4 \\
\hline \multirow{2}{*}{ Explanatory variables } & VC. & $0.129(1.31)$ & $0.003(0.35)$ & RNPAT & R\&D \\
& VCshare & & & $0.239(-0.41)$ & $-0.100(-2.17)$ \\
Control variable & LNSIZE & $0.121(2.00)$ & $-0.013(-3.22)$ & $0.208(1.98)$ & $-0.004(-0.67)$ \\
& AGE & $-0.001(-0.05)$ & $0.000(0.01)$ & $0.000(0.01)$ & $-0.001(-0.99)$ \\
& HOE & $0.034(-0.08)$ & $0.024(-0.87)$ & $0.584(1.01)$ & $-0.003(-0.10)$ \\
& ALR & $0.182(0.62)$ & $-0.011(-0.46)$ & $0.379(0.91)$ & $-0.053(-2.13)$ \\
cons & & $0.172(-0.24)$ & $0.193(4.16)$ & $-0.921(-0.31)$ & $0.145(2.18)$ \\
Number of variables & & 139 & 139 & 139 & 139 \\
Revised R square & & 0.042 & 0.049 & 0.099 & 0.101 \\
\hline
\end{tabular}

Notes: The values in parentheses represent t-statistics. 
Table 3. Results of the return of venture capital on the Sci-tech Innovation Board to corporate technological innovation

\begin{tabular}{llllll}
\hline & Model & 5 & 6 & 7 & 8 \\
\hline \multirow{2}{*}{ Explanatory variables } & & LNPAT & R\&D & LNPAT & R\&D \\
& VCshare & $-0.230(-0.33)$ & $0.009(0.79)$ & & \\
Control variable & & & $0.576(0.79)$ & $0.028(0.37)$ \\
& LNSIZE & $0.27(7.05)$ & $0.001(7.05)$ & $0.222(5.16)$ & $-0.09(-1.19)$ \\
& AGE & $0.006(0.85)$ & $-0.000(-0.39)$ & $0.009(1.22)$ & $-0.000(-0.03)$ \\
& HOE & $0.292(0.97)$ & $-0.032(-0.58)$ & $0.241(0.68)$ & $-0.088(-1.28)$ \\
cons & ALR & $0.179(0.95)$ & $-0.150(-4.24)$ & $0.156(0.75)$ & $-0.123(-3.13)$ \\
Number of variables & & $-0.401(-3.08)$ & $0.145(1.90)$ & $-0.970(-1.91)$ & $0.259(3.05)$ \\
Revised R square & & 184 & 184 & 128 & 128 \\
\hline
\end{tabular}

Notes: The values in parentheses represent t-statistics.

\section{ROBUSTNESS TEST}

In Table 3, the robustness test of this article is mainly aimed at the regression result of the venture capital shareholding ratio of the science and technology innovation board to the enterprise's technological innovation. This paper uses the ratio of the number of patents to the proportion of R\&D investment to represent innovation efficiency. It uses innovation efficiency as a new explained variable to perform regression. The regression results find that the coefficient of venture capital shareholding (VCshare) is significantly positive at the level of $1 \%$. This shows that the regression results of the previous model are more reliable and that venture capital can promote the technological innovation of enterprises as a whole.

\section{MECHANISM INSPECTION OF VENTURE CAPITAL'S INFLUENCE ON ENTERPRISE TECHNOLOGICAL INNOVATION}

This program is about identifying three mechanisms for venture capital to promote enterprise technological innovation. The author uses the stepwise regression method to test the three mediating effects of optimizing resource allocation, diversifying risks, and resolving information asymmetry and then calculates the size of each mediating effect through calculations and compares them.

\subsection{Risk Diversification}

According to the shareholder activism theory, after venture capital enters the target company, it will often play the role of an active shareholder and improve the corporate governance level of the target company [14]. On the one hand, the entry of venture capital can effectively curb the problem of "one share dominance" in startups. On the other hand, venture capital encourages the innovative power of corporate $R \& D$ personnel through equity incentives and other methods. Therefore, the entry of venture capital will change the equity structure of the target company to a certain extent and make the original equity concentration of the target company change to a certain extent.

In summary, the mediating effect of risk diversification exists in the influence mechanism of venture capital on enterprise technological innovation. After the intervention of venture capital, the equity structure of the target company can be changed to reduce the concentration of equity to diversify the R\&D risk and managerial risk [15].

\subsection{Resolve Information Asymmetry}

This section discusses the impact mechanism of venture capital by reducing the information asymmetry between the invested company and external financiers, helping target companies to obtain more external financing, thereby promoting their technological innovation.

In summary, the mediating effect of the information asymmetry mechanism in venture capital's technological innovation is significant. The support for target companies not only improves the internal environment by providing funds and participating in management but also releases positive signals to external investors through their own reputation and information advantages in the 
industry, reduces information asymmetry, and improves the external environment of the investment company makes it easier for target companies to obtain financing after the entry of venture capital [16]. The increase in the number of financing events has prompted them to have sufficient funds to increase $R \& D$ investment so that companies have the opportunity and motivation to try invention patents and utility model patents Because these two patents have the largest technical content, require the most capital investment, and have the greatest risk; In contrast, the design patent has a lower technical content, requires less capital, and has lower risks, so the target company gets more credit. Pledged loans have little effect on its output, so the regression coefficient is also not significant. The size of the intermediary effect is far smaller than the impact on invention patents.

\subsection{Test of the Moderating Effect of Shareholding Ratio and Entry Period}

The previous article proves that venture capital has a significant positive promotion effect on enterprise technological innovation. This section mainly explores the proportion of venture capital holdings and the adjustment effect of the entry period. The author first examines the moderating effect of venture capital in the target company's shareholding ratio. Then it examines the moderating effect of venture capital on technological innovation in different periods of the target company.

The results of the benchmark regression have shown that venture capital has a promoting effect on enterprise technological innovation. The following further explores the role of venture capital's shareholding ratio and the adjustment effect of the entry period. First, use this section to test the moderating effect of venture capital's shareholding ratio

When the shareholding ratio of venture capital is less than $24 \%$ [17], on the one hand, venture capital has a poor sense of "ownership" in the target company, and venture capital will minimize post-investment management behavior and reduce management costs. On the other hand, at this time, venture capital behavior More similar to "free rider", the phenomenon of "short-sightedness" is relatively serious, and the wind.

The investment will focus more on obtaining more investment income when exiting; on the other hand, venture capital has a weaker voice in the target company and cannot effectively influence the company's decisionmaking [18]. At this time, the intervention of venture capital provides limited financing support and valueadded services for the target company, and the motivation and ability to intervene in the allocation of human capital and implement equity incentives are insufficient, which inhibits the improvement of the target company's innovation output. However, when the proportion of venture capital holdings exceeds $24 \%$ [17], the venture capital has a sense of "ownership" and a strong voice in the enterprise. It has sufficient motivation to optimize the human capital allocation of the target enterprise, implement equity incentives, provide value-added services, and significantly promote the innovation output of enterprises.

In the initial stage and the mature stage, this adjustment effect becomes negative. The moderating effect of venture capital on the technological innovation of enterprises in different periods is very different [19]. The influence of venture capital intervention on the output of the target enterprise's invention patents in different periods shows a trend from positive to negative. During the expansion period, the entry period of venture capital has a significant promotion effect on enterprise innovation output and the regulation effect is the strongest.

\section{CONCLUSIONS}

This article uses sci-tech innovation board and growth enterprise board listed companies as samples. It uses empirical methods to analyze the impact of venture capital participation and venture capital's shareholding ratio on corporate technological innovation. The above regression results show that the entry of venture capital in GEM listed companies has not played a role in the technological innovation of the invested companies.

Significant promotion effect, but the proportion of venture capital shares held by listed companies on the Science and Technology Innovation Board has a significant promotion effect on the innovation output of enterprises and the improvement of innovation efficiency. On the one hand, the reason for the foregoing phenomenon may be that due to the different listing conditions on the ChiNext and the Science and Technology Innovation Board, venture capital companies are more likely to capture corporate interests in the ChiNext environment. On the other hand, the strict information disclosure system of the Sci-tech Innovation Board helps reduce the speculative behavior of venture capital companies to a certain extent. For the Sci-tech Innovation Board companies, venture capital is more willing to assist their long-term development than profitmaking short-term benefits.

On the whole, for a high-tech company, the introduction of venture capital is very useful to improve its technological innovation level. Venture capital can help the company realize value appreciation in many ways. However, the development of venture capital in my country is still on the rise, and the innovative effect of venture capital on enterprises is not obvious. Therefore, the venture capital industry must build a sound service system, improve its overall strength, actively invest in enterprises, and seek common development with enterprises. 


\section{REFERENCES}

[1] Zhang, K., Gu, L., Research on the mechanism of venture capital promoting enterprise innovationAn empirical analysis based on China's information technology industry, Wuhan Finance, 2020, issue. 08, pp. 37-47. [in Chinese]

[2] Li, J., Liu, D., An S., Research on the impact of venture capital characteristics on enterprise technological innovation, Shanghai Finance, 2018, issue. 07, pp. 75-84. [in Chinese] DOI: https://doi.org/10.13910/j.cnki.shjr.2018.07.012

[3] Shen, L., The impact of venture capital on the independent innovation of small and medium-sized enterprises-based on the empirical data of the Growth Enterprise Market, Securities Market Herald, 2015, issue. 01, pp. 69-64. [in Chinese]

[4] He Y., Zeng X., Ma H., On the impact of venture capital on technological innovation, Finance and Accounting Monthly,2020, issue. 05, pp. 13-19. [in Chinese] DOI: https://doi.org/10.19641/j.cnki.421290/f.2020.05.003

[5] Wang L., Yuan L., Biased technological progress, industrial structure changes and China's factor income distribution pattern, Economic Research Journal, 2018, issue. 11, pp. 115-131. [in Chinese]

[6] Wen J., Feng G., Venture capital and enterprise innovation: the trade-off perspective of "value added" and "grabbing", Economic Research Journal, 2018, issue. 02, pp. 185-199. [in Chinese]

[7] Lu Y., Zhang Y., Jia R., Li J., "Syndicate" venture capital and enterprise innovation, Journal of Financial Research, 2017, issue. 06, pp. 159-175. [in Chinese]

[8] Dong J., Wang L., Will venture capital affect the strategic choice of start-ups? -Literature review and theoretical framework, Foreign Economics and Management, 2017, issue. 02, pp. 36-46. [in Chinese] DOI:

https://doi.org/10.16538/j.cnki.fem.2017.02.003

[9] Chen S., He W., Zhang R., Venture capital and enterprise innovation: Impact and potential mechanism, Management World, 2017, issue. 01, pp. 158-169. [in Chinese] DOI: https://doi.org/ 10.19744/j.cnki.11-1235/f.2017.01.014

[10] Li J., Yang B., Pan Z., Government subsidies, equity concentration and sustainability of corporate innovation, China Soft Science, 2016, issue. 06, pp. 180-192. [in Chinese]

[11] Feng Z., Wen J., Liu Q., Research on the nonlinear relationship between venture capital and technological innovation-PSTR analysis based on provincial data, Industrial Economic Research, 2016, issue. 02, pp. 32-42. [in Chinese] DOI: https://doi.org/ 10.13269/j.cnki.ier.2016.02.004

[12] Dong J., Peng S., The signaling role of venture capital in acquisitions_-An empirical study based on non-listed companies, Review of Investment Studies, 2015, issue. 08, pp. 124-136. [in Chinese]

[13] Wang L., Yuan Li., Will capital mismatch induce total factor productivity loss?, Statistical Research, 2014, issue. 08, pp. 11-18. [in Chinese] DOI: https://doi.org/10.19343/j.cnki.111302/c.2014.08.002

[14] Guo T., A review of shareholder activism, Research of Finance and Accounting, 2021, issue. 04, pp. 2836. [in Chinese]

[15] Liang Y., On risk control in venture capital, Accounting Learning, 2020, issue. 09, pp. 217-219. [in Chinese]

[16] Li J., The influence of information asymmetry on technology innovation financing and its governance, Research of Finance and Accounting, 2011, issue. 10, pp. 78-80. [in Chinese]

[17] J. Lerner, R. Nanda, Venture capital's role in financing innovation: what we know and how much we still need to learn, Journal of Economic Perspectives, 2020, issue. 03, pp. 237-261. DOI: https://doi.org/10.1257/jep.34.3.237

[18] Fu Y., A review of the influence of venture capital on corporate governance, Journal of Times Finance, 2012, issue. 18, pp. 195. [in Chinese]

[19] Zhang Z., Xue H., Research on the influence of venture capital on the development of high-tech enterprises, Modern Business, 2020, issue. 04, pp. 117-119. [in Chinese] 